\title{
Sources of inocula influence mycorrhizal colonization of plants in restoration projects: A meta-analysis
}

Mia R. Maltz \& Kathleen K. Treseder

University of California, Irvine

\section{Introduction}

Researchers have long investigated the role of mycorrhizal fungi in ecological restoration

- Inoculation may increase mycorrhizal colonization and provide benefits to plants in restoration projects

- It is unclear whether inoculation has consistent effects across ecosystem types, if it has long-term effects on colonization, and whether sources of inocula differ in their effectiveness

\section{Hypotheses}

Additions of mycorrhizal inocula would result in sustained increases in percent root length colonized (PRLC) of plants grown in the field

- Additions of mycorrhizal inocula would result in improved plant growth in field restoration projects

- Whole inocula from neighboring reference ecosystems would elicit larger increases in PRLC than would commercial inocula

\section{Study Design}

- We performed a meta-analysis of published restoration studies across a variety of ecosystems to examine the effects of mycorrhizal inoculation on mycorrhizal establishment and plant growth under field conditions

- Our meta-analysis included trials from:

$$
\begin{aligned}
& \text { - a variety of geographic locations } \\
& \circ \text { disturbance types } \\
& \text { ○ ecosystem types }
\end{aligned}
$$

- Trials were conducted on landscapes degraded primarily by anthropogenic activities such as agriculture, logging, construction, desertification, grazing, and mining

\section{Results}

Inoculum improved (1) root colonization by mycorrhizal fungi and (2) plant growth, unless commercial inoculum was used.
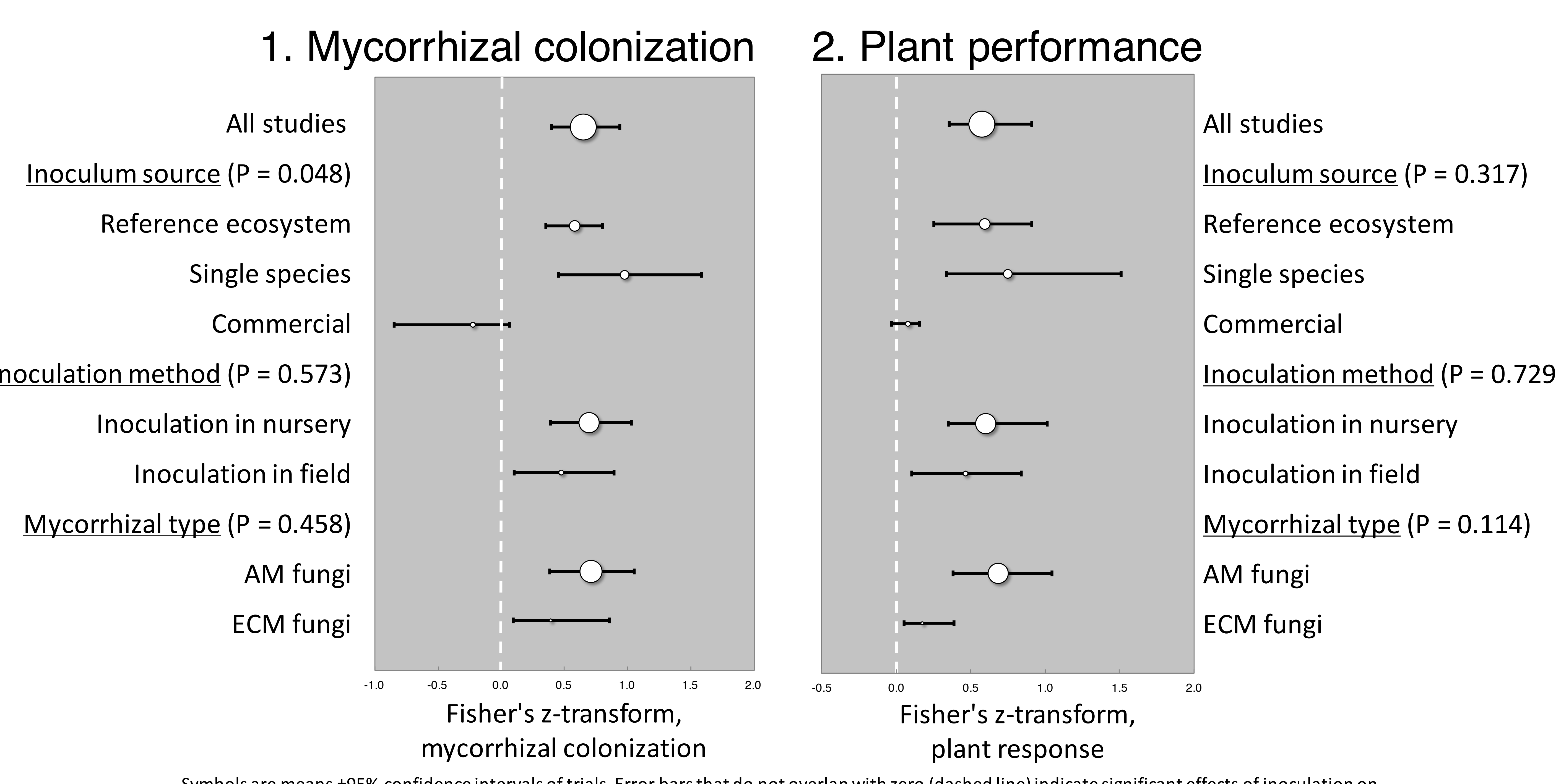

percent root length colonized by mycorrhizal fungi or plant response. Symbol size is proportional to number of trials $(4-28)$.
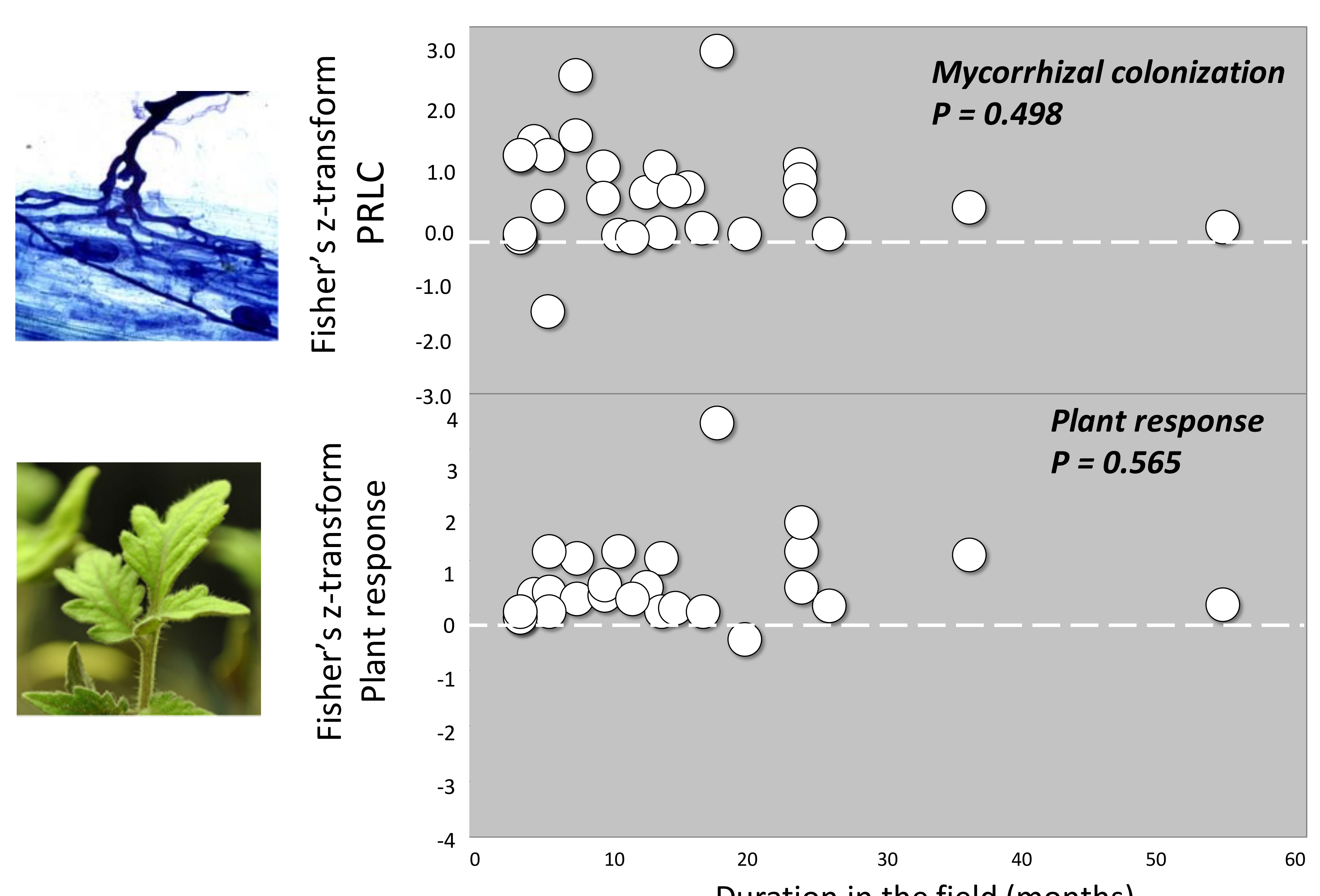

Duration in the field (months)

\section{Conclusions}

- Restoration ecologists can intentionally increase the abundance of mycorrhizal fungi in degraded ecosystems, and thus improve the establishment of native plants.

- The beneficial effects of inoculation do not attenuate over time

- When fungal inoculum from a reference ecosystem or a single fungal taxon was used to inoculate field restoration projects, PRLC increased significantly more when than when commercial inoculum was used

\section{Implications for Practice}

- Mycorrhizal restoration via inoculation is a simple means to improve mycorrhizal abundance and plant performance in restoration projects.

- If whole inoculum from reference ecosystems is easily accessible, it may be more efficient and cost-effective than the use of commercial inoculum.

- An initial investment in mycorrhizal inoculation could provide benefits for up to several years in the field.

\section{Acknowledgements}

Sincere thanks to the authors of all studies included in this meta-analysis. This study was funded by the Center for Environmental Biology grant to K. Treseder and M. Maltz, entitled Fungal Facilitators of Ecosystem Services. 